\title{
Addressing the Socio-Spatial Challenges of Innovative Learning Environments for Practicum: Harmonics for Transitional Times
}

\author{
Emily Nelson and Leigh Johnson
}

\begin{abstract}
A shift to Innovative Learning Environments (ILEs) in New Zealand schools is a current Ministry of Education strategic direction challenging how we as teacher educators prepare candidate teachers (student teachers or trainee teachers) to teach in these emerging environments. Candidate teachers in our primary teaching degree increasingly are placed in ILEs on practicum as these develop in schools in our geographic area. Our students report anecdotally that teaching in ILEs poses them steep and novel challenges around how they plan, teach, assess, manage students and learning, as well as work collaboratively with associate teachers and, increasingly, other colleagues. With our current programme underpinned by a more conventional image of teaching and learning, and schools transitioning between conventional and arguably more innovative, bespoke environments, we wondered how our students navigated the novel pedagogical and physical configurations they encountered in ILEs on practicum. We conducted focus group interviews with our candidate teachers and recent graduates who had completed one or more practicum in an innovative learning environment (as defined by the practicum school). We explored participants' perceptions of the particular demands ILEs created for them. Utilising Lefebvre's (The production of space. Trans. Blackwell, Cambridge, MA, 1991) socio-spatial trialectic and Monahan's (Built pedagogies \& technology practices: designing for participatory learning. Palo Alto, CA, 2000) notion of "built pedagogy" in this chapter we identify key socio-spatial entanglements, or harmonics, that emerge from our analysis and explore how these inform how we might better prepare our candidate teachers in these transitional times.
\end{abstract}

\section{The Material Disruption of ILEs for the Education Sector}

Emerging from the OECD, the concept of innovative learning environments (ILEs) acts to re-conceptualise education for the supposed needs of contemporary society (Cleveland \& Fisher, 2014). Based on transversal principles of how children learn

E. Nelson $(\varangle) \cdot$ L. Johnson

Eastern Institute of Technology, Taradale, New Zealand

e-mail: enelson@eit.ac.nz 
and the conditions that support, learning and teaching in ILEs is underpinned by commitment to teacher and learner collaboration, student agency, flexible learning arrangements, ubiquitous technology use and inquiry pedagogies that are enacted in collective learning hubs. In the New Zealand context, the transition from conventional cellular configurations of teaching and learning to the collaborative and flexible hubs of ILEs was prompted by a policy imperative (Ministry of Education, 2011) requiring that all schools modernise their teaching and learning environments by 2021 (this has more recently been softened to "encourage" schools to develop ILEs if this is their preferred direction). However, the "spatial literacy" (Imms, Cleveland, \& Fisher, 2016, p. 6) required to enact learning and teaching in ILEs adds a "significant layer of complexity" (Fletcher, Mackey, \& Fickel, 2017, p. 71) for teachers. For instance, the more collaborative teaching practices these spaces lend themselves to, come with consequent expectations on teachers-being more adaptive, flexible and relational (Whyte, 2017). This can represent significant material disruption for many teachers, students and parents. Thus, it can be argued that implementing ILEs involves more than a simplistic assumption that changes to buildings will shift and support changes to pedagogy. As Bradbeer et al. (2017) foreground, the change prompted by ILEs involves the "embodiment" of "pedagogical beliefs in the day-to-day practices of the school" (p. 22) and the need to engage with educator, parent and student conceptions of schooling, learning and teaching (Benade, 2017).

Amongst this dramatic shift in conceptualising learning and teaching in schools, preservice education practices are challenged to respond to this changing view of how we should learn and teach. Not only does a shift to ILEs involve significant capability development for experienced educators and leaders (Whyte, 2017), such a shift poses significant challenges for candidate teachers, and initial teacher education (ITE) providers. These challenges are intensified by the reality that at the time of writing, approximately $75 \%$ of teaching and learning in schools continues to be within singlecell learning spaces with teacher-led pedagogies, meaning ILEs and their attendant practices are still in the minority (Imms, Mahat, Byers, \& Murphy, 2017). Preservice teacher education needs to straddle this diversified reality when preparing beginning teachers for teaching. During the transitional time we are witnessing, with preservice programmes predicated largely on conventional visions of learning and teaching, candidate teachers are challenged to "translate" their campus learning experiences into appropriate practices for the bespoke ILEs they may inhabit on practicum when their reference points are more than likely conventional.

The authors practice as teacher educators within a New Zealand regional, practicebased primary teaching degree. The degree was collaboratively conceptualised, designed and enacted between a group of local Principals, the ITE provider and a group of learning design specialists from other ITE institutions and professional development organisations. Candidate teachers engage two days per week in campusbased classes and two days per week engaged in "school-based learning" tasks within one partnership school. In addition to the weekly school-based learning programme candidate teachers also participate in block practical placements across the three years of their degree. In 2015 a minority of our candidate teachers began to experience ILEs on practicum. Additionally, given the close nature of our partnership, the 
teacher educator team was increasingly challenged to adapt school-based learning and practicum requirements to respond to the bespoke configurations of the ILEs emerging in our partnership schools. For us space had become a "prominent consideration" (Bradbeer et al., 2017) as we endeavoured to disrupt our taken for granted beliefs about learning and teaching and consider how to prepare our candidate teachers for ILEs. We wondered: With more candidate teachers experiencing ILEs on practicum, how were they grappling with these new environments and the pedagogical challenges these posed, given that we were simultaneously grappling with the implications of these emerging socio-spatial arrangements for our programme curriculum, pedagogy and supervisory practices? This issue framed the research being presented in this chapter.

\section{Theoretical Framing}

ILEs hold the capacity to re-conceptualise both the social relationships and spatial arrangements of learning and teaching. To understand this potential, the authors utilise Lefebvre's (1991) socio-spatial trialectic and Monahan's (2008) notion of built pedagogy that "make sense" of these environments, the pedagogies they promote and what these mean for candidate teachers navigating ILEs on practicum. Rather than being an inert container to house social activity, Lefebvre views space as socially produced, alive and layered with the perceptions, experiences, and theorising of those who inhabit them in particular ways. From a socio-spatial perspective "learning spaces and the uses made of these are created and sustained together in a mutually constitutive relationship" (Mulcahy, Cleveland, \& Aberton, 2015, p. 6). We agree that space is always political, imbued with discourses and ideologies, dynamic, and open to ever-present possibilities of disruption and transformation (Lefebvre, 1991; Monahan, 2008).

Lefebvre identifies three spaces that taken together form a socio-spatial trialectic. The first "perceived space" frames the familiar and the expected. In the context of preservice education this space includes "course content and assessment, field placements, school and university pedagogies and practices" (Ryan, 2011, p. 887) and interrelationships between all these practices. The second "conceived space" comprises the "ideals"- -how "society should be" (Ryan, 2011, p. 887). In the context of initial teacher education conceived space refers to the "professional standards, course accreditation and the structure of university and school procedures to produce 'ideal' future teachers" (p. 887). The third "lived space" represents the coming together of the perceived and conceived through the in-action decisions of social actors such as candidate teachers, associate teachers and teacher educators. The lived space is a space of imaginings and possibilities, "the space where preservice teachers can make choices about which [...] practices/ideologies they might interrupt or resist and how they might do so in their own time and space" (p. 888). 
Ryan argues that the perceived, conceived and lived spaces entangle, all three continuously enacted, exerting influence on each other and producing particular harmonics of embodied practice.

Monahan's (2000) notions of "built pedagogy" and "embodied material conditions" theoretically locate our work. Monahan contends that "Built environments enable and constrain certain modes of social action and interaction, educational structures embody curricula and values by design" (p. 1). The "embodied material conditions" of a space generate "messy materialities" and investigation is needed to explore the ways in which the material, "shape[s] lives and establish[es] social orders" (Monahan, 2008, p. 99).

Instructing candidate teachers to negotiate these intertwined spaces of ILEs on practicum is under-researched. They are expected to teach in ILEs whilst simultaneously negotiating the high-stakes requirements of the practicum as an assessed experience. In practicum experiences, "pre-service teachers are expected to make the connections between often-contradictory spaces with little or no guidance on how to negotiate such complex relationships" (Ryan, 2011, p. 881). With the advent of ILEs, we contend the challenge is intensified. ILEs are changing the education landscape so rapidly that our formal institutional change and review processes are inadequate to respond in a timely manner in the short-term. Instead we decided to talk directly with our candidate teachers who had been successful in ILE practicums, to find out how they navigated learning to teach in these spaces on practicum in the aim of re-conceptualising our own practice, and programme, informed by them.

\section{Methodology}

Our qualitative, small-scale exploratory research explored how our candidate teachers enacted learning to teach in ILEs on practicum. We were interested in how they translated their beliefs, and those they encountered on campus and in schools, into embodied day-to-day practices (Bradbeer et al., 2017). Nine candidate teachers participated in the study; each of whom had experienced at least one practicum in an ILE during years two or three of their degree. This small sample size is indicative of the emergent nature of ILEs in our geographical area at the time of conducting this research, and the small cohort sizes of our boutique programme.

We utilised focus group interviews (Morgan, 2004) as our data generation strategy. This approach enabled us to explore the challenge of ILEs for practicum from the candidate teachers' perspectives, in a way in which perspectives shared could be challenged, augmented and contrasted. We anticipated a focus group approach would also provide the reflective and educative opportunity for participants to reflect and debrief their learning around teaching in ILEs that Whyte (2017) identifies as key to making sense of practice as part of learning to teach. The three 45-60 minute focus group interview transcripts generated were audio-recorded and professionally transcribed. 
One main research question framed our research: "How do candidate teachers learn to teach in Innovative Learning Environments (ILEs) on practicum?"

We developed our focus group interview protocol around areas central to practicum that we anticipated might be different in an ILE to a conventional singlecell classroom experience. Our protocol invited participants to discuss: characteristics of ILEs experienced, approaches to planning, approaches to pedagogy, support and guidance needed and received, necessary skills and dispositions for teaching, technological capability required and practices that supported student ownership of learning.

We utilised a constant comparative approach (Silverman, 2005) to analyse the focus group interview transcripts. The constant comparative approach involved us firstly conducting an emic data analysis to generate an emergent framework of themes important to participants' experiences in their ILE practicums. For example we identified "tinkering" as an emic code that described a disposition towards candidate teachers playing with the affordances of particular technology apps before enacting these with their students. Three participants discussed tinkering as an approach that they used to prepare for teaching that became more important in ILEs because of the need to fit in with other teachers.

We developed this emic coding framework during analysis of the first interview transcript, then applied it successively to the second and third transcripts, refining the emergent framework with each iteration and re-applying new codes until we were satisfied we had accounted for all the data. We conducted the data analysis separately in the first instance, then met together to debate, define and provide examples for each code until we reached consensus.

We also conducted an etic analysis of the data by using the broad topics of our focus group interview questions, Monahan's (2000) elements of built pedagogy and Lefebvre's three spaces as codes. For example Monahan's notion of "fluidity", or "Design of space for flows of individuals, sight, sound and air" (n.p.) enabled us to engage with participants' descriptions of the characteristics of ILEs to identify the flows they expected to find and the "lived" realities of the bespoke practicum environment. Through this we realised participants theorise ILEs more than we had expected, given very little consideration of ILEs in our programme curriculum at the time.

To illuminate the socio-spatial we used axial coding processes to produce socio-spatial harmonics, the interconnections we identified between the perceived, conceived and lived spaces that participants discussed. Codes that co-occurred, and that we deduced were related, were linked together to produce three harmonics that addressed how candidate teachers learned to teach on an ILE-situated practicum.

The harmonics were:

1. Collegial Collaboration;

2. Responding to the particular rhythmical practices of ILEs and

3. Negotiating messy materialities versus the "ideals" of teaching in ILEs.

We present these harmonics as themes in the sections that follow, after describing the characteristics of the ILEs our participants inhabited on practicum. 

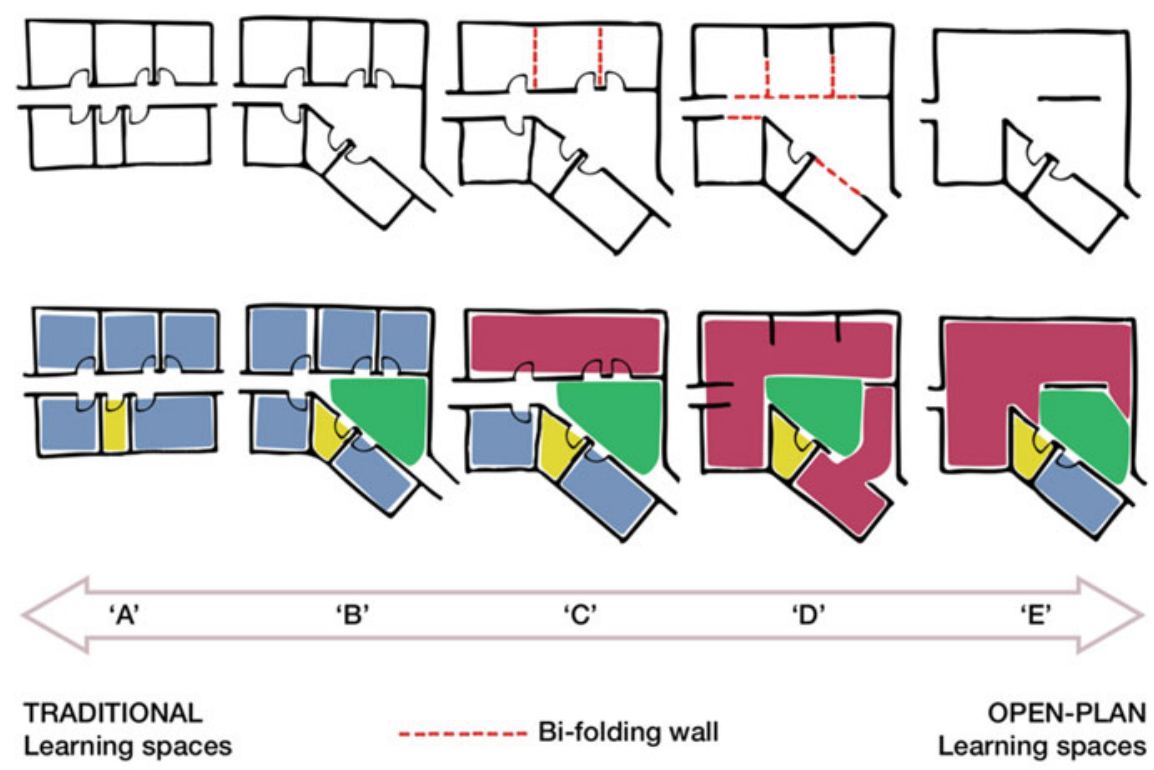

'B'

'C'

'D'

'E'

Learning spaces
LeaDITIONAL

\section{Store room \\ Store room}

- Bi-folding wall

Solid wall

Fig. 1 Typology of spatial design (source Imms, W., Mahat, M., Byers, T, \& Murphy, D. (2017). Reprinted with permission from the ILETC project)

\section{Characteristics of the ILEs}

The nine participants drew on their experiences of 11 ILE practicums in the focus group interviews. The contexts are presented in relation to Dovey and Fisher's (2014) spatial typology adapted by Imms, Mahat, et al. (2017) (Fig. 1). ${ }^{1}$

All the ILE contexts the participants experienced were retrospective adaptations of existing classrooms and other spaces (school hall, cloak rooms, etc). All ILEs were in their first 2 to 3 years of operation, with most in their first year. Table 1 arranges the 11 practicums in relation to the spatial typology presented.

Table 1 shows that four of the ILEs encountered were characterised as type A environments, essentially involving between one and three teachers teaching collaboratively within a traditional classroom space. Participants described experiences within five type $\mathrm{C}$ environments where classrooms had been modified to enable the use of breakout spaces and flexible pedagogical arrangements. Interestingly, these

\footnotetext{
${ }^{1}$ This has been developed over time through various LEaRN projects, but acknowledgement must be made to Drs. Kenn Fisher and Kym Dovey for the original conceptualisation; Dovey, \& Fisher, (2014). Also to Dr. Pippa Soccio for the graphic representation.
} 
Table 1 Spatial typology breakdown

\begin{tabular}{l|l|l}
\hline Cluster type & Characteristics & Number \\
\hline A & Traditional classroom & 4 \\
\hline B & Traditional classrooms + street space & \\
\hline C & Convertible classrooms & 5 \\
\hline D & Convertible street space & 1 \\
\hline E & Dedicated commons & \\
\hline Unsure & & 1 \\
\hline
\end{tabular}

type $\mathrm{C}$ environments were identified as the least prevalent type of ILEs in New Zealand in the initial findings of the ILETC project (Bradbeer et al., 2017), but characterised five of the 11 spaces encountered by our participants.

\section{Collegial Collaboration}

Supporting teachers to collaborate forms an underpinning ubiquitous ideal and design principle of ILEs (Bradbeer, 2017). However, participants described the complexity collaboration produced for their supervisory relationships on practicum. Teaching on practicum in ILEs upscaled practicum supervision relationships from a predominantly one-to-one mentoring relationship with one associate teacher, to a one-to-many collegial relationship.

The spatiality of the ILE context required participants to plan collaboratively with multiple colleagues, taking responsibility for different groups of learners across curriculum areas and year levels.

The way I planned is that I planned in conjunction with both teachers that were in the classroom. So it was after school we would talk about which parts I'd be taking and which parts they'd be taking. So I had responsibility for the year fours for maths, so I'll plan just strictly for the year fours and the other teacher would have responsibility for the year threes.

The rhythm of planning and implementation was intensified in terms of it happening every day with expectations around implementation for the next day. This is considerably different to the expectation in our preservice curriculum that candidate teachers would plan in advance for stable groupings of learners (e.g. a reading group, or multiple reading groups) and that over-writing be used on the formal lesson or unit plans to indicate where adjustments would be made for insights gained from working with each group. Participants described opportunities for enhanced collaborative responsibility for planning positively, emphasising the support and feelings of competence they gained.

I felt that my AT [associate teacher] supported me a hundred percent. The other teacher let me take over her job. It was great, it had its downfalls but, yeah. 
Despite the complexity produced, the increased access to colleagues supported participants with their confidence around planning and teaching.

If you've got an idea and you're not entirely sure you can clarify it with someone [...] in my case there was a really experienced teacher and then a teacher that had only just come out of her practice. [...] So that helped me develop and also I felt confident approaching a lesson knowing that I was well prepared.

These feelings of value and competence seemed to be reinforced by the fact that often the associate teachers themselves were new to teaching in ILEs, creating space for candidate teachers to contribute to how the material disruptions (Monahan, 2008) and discourses around teaching in new ways in ILEs were negotiated.

\section{Responding to Rhythmical Practices of ILEs}

Within "built pedagogy" "the design of learning spaces must take into account how the space-time compression engendered by information technology affects learning rhythms ... built pedagogies ... emerge relationally through rhythmical practices that occur within these spaces" (Monahan, 2000, n.p.). With participants placed in hubs with responsibility for learners from up to three "home classes", they noted this arrangement caused them difficulty with getting to know the needs of learners in short timeframes:

At [School] we had a three week rotation on PE where one teacher took the same thing just three times in a row and the three home classes rotated round each teacher. So it was, yeah you just plan for the general feel of the class.

Participants discussed how they planned for the feel of the class in response to short timeframes and being expected to teach students from within larger groups. Planning for the "feel" of the class is not a practice promoted in our preservice curriculum. The compressed time scale of planning in ILEs disrupted expectations of the perceived space of campus where "knowing your learner" and "diagnosing learning needs" are important aspects of pedagogy that traditionally take place over a longer time frame and are informed by data.

The rhythmical practices of ILEs also posed a classroom management challenge for candidate teachers:

Managing lots of students. I think being able to think on the spot and just, well, reflect on action isn't it, yeah how to make those quick changes to make improvements.

ILEs intensify the need for candidate teachers to enter practicum with a sound and solid understanding of learning progressions to make quick collaborative decisions about next learning steps as a key part of the collaborative and flexible teaching role. 


\section{Reconciling the Rhetoric with the Messy Materialities of Teaching in ILEs}

Many participants described struggles with the messy materialities of ILEs which, at times, differed from the rhetoric of ILEs as innovative and an advance on conventional classrooms. Participants mediated their in-action decisions through the "shoulds" they brought to the ILE practicum, gained from the perceived space of campus and from broader media coverage of ILEs.

The one I was in, it was in a hall, so the hall had been taken out but it was just an open plan setting. It had a couple of different level tables, bean bags, but nothing really that stood out to be what an ILE is for me. It was just this bunch of furniture put into a room, basically.

This perspective resonates with the "confusing array of designs" (Bradbeer et al., 2017, p. 24) that constitute ILEs. Candidate teachers must interpret and respond to the bespoke nature of the ILE on practicum.

Attending to messy materialities also included negotiating informal furniture arrangements whilst they taught, for example bean bags.

Can I just interrupt you, the bean bags were an absolute pain in the arse. They were absolutely horrible, like good for relaxing, but not for when you want to have a learning environment, because they're just squeaking and moving around all the time.

Noise and distraction produced by teaching alongside other teachers and groupings of students within the same space challenged the novice teachers also.

Yeah I think the noise level was an issue when I was in there. I was taking one class and another teacher was taking her class and if they got up to do an activity for whatever reason, it would distract the class I was teaching and the noise was just too distracting, personally.

Most participants linked issues with acoustics to spatial design.

Well, the one at [School,] that was sound-proofed quite nicely and the L shape that it went in, you couldn't really hear the noise from this room when you were in either of these two home spaces here. The teachers had it set up quite well. Even if the kids were talking it was a bit of a quiet hum. The one I was in this year was, yeah, just everything seemed quite close together and if you were sitting here doing some teaching and there's another teacher there, it was difficult to block out the noise I guess from the other group of kids.

Integrating digital technologies into their teaching in practice did not always align with the realities of the ILE. Campus curriculum highlighted the importance of purposeful integration of technology as an aspect of effective pedagogy:

[Teacher educator] touched on it when we did one of the courses. The technology [...] should enhance or morph the task into something deeper than what could be done without the device.

Participants struggled with technology integration that seemed to promote student independence at the expense of rich learning. One participant discussed Pic Collage posters as an example. 
It's not that there's not a place for a pic collage like that 'cos there is a place for that, it might be on your reading task board you know, but it's not teaching, that's not using technology for learning [...] I've got so little time in a day, I can't imagine just getting them to make a poster unless it had valuable learning within it, it would just, there's just not enough time for that sort of stuff.

Dominant discourses of IT also promise "democratic access" and " "friction-free" exchanges of capital' (Monahan, 2008, p. 89). However, participants encountered proprietary barriers with some of the digital platforms their schools subscribed to limit their ability to enact teaching fully in the virtual spaces of their ILE hubs. As one participant described:

I only had access to Teacher Dashboard through my teacher's laptop so I only used it in the morning to send my stuff out, 'cos it was a programme on her laptop. I didn't actually have access to it while I was teaching so I couldn't look at the children's screens unless you're actively there and it's hard. What do you do when you're teaching a group to make sure that you can still monitor those children?

The pedagogical expectation of monitoring student learning was disrupted in the lived space of the ILE practicum. Even for those participants who described having limited access to learning management systems, they were often not able to take full advantage of the affordances of these platforms because they did not have full teacher access. This messy materiality created a tension with the entangled expectations from the preservice programme that encourage e-learning as an aspect of effective pedagogy (Ministry of Education, 2007) and the reality of not being able to fully embody this aspect of the teaching role.

\section{How Do Candidate Teachers Learn to Teach on Practicum?}

Despite some misalignments between the ideal and realities of the lived ILE practicum, our findings suggest that the material disruption (Monahan, 2008) ILEs create for experienced teachers opened up new opportunities for candidate teachers to inhabit the teaching role on practicum as respected colleagues. In all cases participants found themselves entering "spaces under construction" where teachers were trialling new spatial and pedagogical practices and seemed to welcome philosophical and decision-making input from their preservice colleagues. This contributed to enhanced feelings of self-efficacy for candidate teachers. Upscaled supervisory relationships opened up opportunities for candidate teachers to enact significant collaboration, and share pedagogical responsibility with multiple colleagues. It appeared that this was welcomed more in the planning than in the teaching process, as distraction and noise level associated with teaching in concert with other colleagues were identified as messy materialities of teaching in ILEs that challenged candidate teachers. 
The ILE practicum did require significant "translation" by candidate teachers between the conventional image of teaching and learning promoted during campusbased learning and the bespoke and dynamic arrangements of the ILEs. The challenge to respond to individual learner needs whilst simultaneously responding to the orchestration challenges of fitting in with two or more collaborating colleagues were significant. Intensified rhythmical practices of ILEs disrupted the vision of stability they were prepared (on campus) to expect. Rather, a fast-paced flexible and highly responsive lived reality of ILEs suggests we need to prioritise practices of collaborating, key learning progressions and management of larger groups in our preservice curriculum to better prepare candidate teachers as adaptive, flexible and relational colleagues (Whyte, 2017).

Disparity of access by candidate teachers to the virtual spaces of ILEs, due to proprietary barriers, constrained them from inhabiting the teaching role fully at a time where this was most needed. In this way technology acted as a barrier to the candidate teachers, providing discourses contrary to those propounded. This dissonance put their success at risk in a number of ways. Candidate teachers must demonstrate their competence as a developing teacher during practicum; it is an assessment task in itself. Fully participating through the technological space of the hub, to relate to learners and to collaborate with colleagues, is vital.

Framing our work with a socio-spatial lens has enabled us to focus on "elements of inter-connection" (Mulcahy et al., 2015) between campus learning and ILE learning for candidate teachers and the harmonics produced. These harmonics challenged our existing thinking. Our participants talked about their campus experiences as supports for engaging with the challenges of ILEs as social spaces new to them, whereas we, initially, viewed campus and practicum as separate spaces. We now think of these spaces as entangled like a mobius strip, with our candidate teachers translating experiences from campus classes, arranged primarily for conventional visions of teaching and learning, and enacting these, under torsion, in ways that address the lived challenges of the ILEs they inhabit on practicum.

Through the process of this analysis the authors found we are thinking about our practice, in a more entangled way. The uses made of technologies by candidate teachers on practicum and their views of "purposeful use", are influencing what, when, how and why we introduce certain technological platforms in our programme. Emphasising the skills of working collaboratively has become an essential aspect of developing pedagogical knowledge in our programme. We need to deepen candidate teachers' curriculum knowledge and knowledge of key learning progressions so that they are better prepared for the intensified pace and collaborative nature of decisionmaking around teaching and learning in an ILE (Alterator \& Deed, 2013). More generally, we need to promote "material disruption" and "messy materialities" as ubiquitous aspects of ILEs and to promote heuristics such as Imms, Cleveland, et al. (2016) spatial typology as key reference points for our candidate teachers to identify the continuities that underpin the bespoke physical and pedagogical design features of their particular ILE. These innovations are essential as a basis for building our candidate teachers' capacities, and our own capacities, to generate adaptive practice in these bespoke spaces during practicum. 
Acknowledgements Data utilised in this research was obtained adhering to the required ethical protocol of the authors' host institution. All images and diagrams are the property of the author, or the author has obtained consent to use them from the appropriate copyright owner.

\section{References}

Alterator, S., \& Deed, C. (2013). Teacher adaptation to open learning spaces. Issues in Educational Research, 23(3), 315-330.

Benade, L. (2017). Is the classroom obsolete in the twenty-first century? ACCESS: Contemporary Issues in Education, 37(1), 28-40. https://doi.org/10.1080/00131857.2016.1269631

Bradbeer, C. (2017, August). Teacher collaboration in flexible learning environments: Rhetoric vs reality. In E. Nelson (Chair), Primary Education Research Symposium. Symposium conducted at Eastern Institute of Technology. Taradale, New Zealand.

Bradbeer, C., Mahat, M., Byers, T., Cleveland, B., Kvan, T., \& Imms, W. (2017). The "state of play" concerning New Zealand's transition to innovative learning environments: Preliminary results from phase one of the ILETC project. Journal of Educational Leadership Policy and Practice, 32(1), 22-38.

Cleveland, B., \& Fisher, K. (2014). The evaluation of physical learning environments: A critical review of the literature. Learning Environments Research, 17(1), 1-28. https://doi.org/10.1007/ s10984-013-9149-3.

Dovey, K., \& Fisher, K. (2014). Designing for adaptation: The school as socio-spatial assemblage. The Journal of Architecture, 19(1), 43-63.

Fletcher, J., Mackey, J., \& Fickel, L. (2017). A New Zealand case study: What is happening to lead changes in effective co-teaching in flexible learning spaces? Journal of Educational Leadership Policy and Practice, 32(1), 70-83.

Imms, W., Cleveland, B., \& Fisher, K. (2016). Pursuing that elusive evidence about what works in learning environment design. In W. Imms, B. Cleveland, \& K. Fisher (Eds.), Evaluating learning environments: Snapshots of emerging issues, methods and knowledge (pp. 3-20). Rotterdam, The Netherlands: Sense.

Imms, W., Mahat, M., Byers, T., \& Murphy, D. (2017). Type and use of innovative learning environments in Australasian schools. ILETC Survey No. 1. Melbourne, Australia: University of Melbourne, LeARN. Retrieved from http://www.iletc.com.au/publications/reports.

Lefebvre, H. (1991). The production of space. Trans. Cambridge, MA: Blackwell.

Ministry of Education. (n.d.). Innovative learning environments. Retrieved from http://ile.educat ion.govt.nz/\#home.

Ministry of Education. (2007). The New Zealand curriculum: For English medium teaching and learning in years 1-13. Wellington, New Zealand: Learning Media Limited.

Ministry of Education. (2011). The New Zealand school property strategy 2011-2021. Retrieved from http://www.education.govt.nz/assets/Documents/Primary-Secondary/Property/ SchoolPropertyStrategy201121.pdf.

Monahan, T. (2000). Built pedagogies \& technology practices: Designing for participatory learning. In T. Cherkasky, J. Greenbaum, P. Mambrey, \& J. Pors (Eds.), Proceedings of the Participatory Design Conference. Palo Alto, CA: CPSR. Retrieved from http://publicsurveillance.com/papers/ pdc2000.pdf.

Monahan, T. (2008). Picturing technological change: The materiality of information infrastructures in public education. Technology, Pedagogy and Education, 17(2), 89-101. https://doi.org/10. 1080/14759390802098581.

Morgan, D. (2004). Focus groups. In S. Hesse-Biber \& P. Leavy (Eds.), Approaches to qualitative research (pp. 263-285). New York, NY: Oxford University Press. 
Mulcahy, D., Cleveland, B., \& Aberton, H. (2015). Learning spaces and pedagogic change: Envisioned, enacted and experienced. Pedagogy, Culture \& Society. Advanced Online Publication. https://doi.org/10.1080/14681366.2015.1055128.

Ryan, M. (2011). Spaces of possibility in pre-service teacher education. British Journal of Sociology of Education, 32(6), 881-890. https://doi.org/10.1080/01425692.2011.614745.

Silverman, D. (2005). Doing qualitative research (2nd ed.). London, United Kingdom: Sage.

Whyte, B. (2017). Collaborative teaching in flexible learning spaces: Capabilities of beginning teachers. Journal of Educational Leadership, Policy and Practice, 32(1), 84-96.

Emily Nelson and Leigh Johnson (NZ) are teacher educators contributing to a practice-based initial teacher education programme at Eastern Institute of Technology. Their research interests focus on preparing preservice teachers for practicum in innovative learning environments and the implications of these environments more generally for initial teacher education. They share interests also in socio-spatial theoretical approaches to learning environments research. Both Leigh and Emily bring backgrounds as primary teachers and professional learning and development facilitators in the primary education sector to their work. Collectively they get excited about student voice and agency, literacy, digital technologies and inquiry learning. They currently bring this passion to their work in teacher education, supporting developing teachers to navigate emergent, innovative practices and environments during their preservice education journey.

Open Access This chapter is licensed under the terms of the Creative Commons Attribution 4.0 International License (http://creativecommons.org/licenses/by/4.0/), which permits use, sharing, adaptation, distribution and reproduction in any medium or format, as long as you give appropriate credit to the original author(s) and the source, provide a link to the Creative Commons license and indicate if changes were made.

The images or other third party material in this chapter are included in the chapter's Creative Commons license, unless indicated otherwise in a credit line to the material. If material is not included in the chapter's Creative Commons license and your intended use is not permitted by statutory regulation or exceeds the permitted use, you will need to obtain permission directly from the copyright holder.

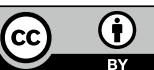

